\title{
Hegemoni Budaya dalam Dinamika Dakwah di Rusia
}

\author{
M. Anwar Syarifuddin \\ UIN Syarif Hidayatullah Jakarta \\ E-mail: ma_syaifruddin@yahoo.com
}

\begin{abstract}
Islam in Russia provided a portrait of the people who have learned from the cultural hegemony. Intimidation efforts against the spread and absorption of some of the ideas will not work, if it does not consider the effort is more persuasive. Despite these efforts can bring consequences unexpected by the authorities, but when it changes gradually raise critical awareness of the traditional Muslim society at that time, about the need to reform mindset that they hold for this, as is the case in the emergence of a reform movement of Islamic thought contained in several prominent stage. This study we will using Antonio Gramsci's ideas which explain that the concept of hegemony by the ruling class is not merely ruled by force, but it must be done in more persuasive ways. In this persuasive ways subordinate classes are forced to learn and see themselves through the lens of the ruler, by the way thanks to the education provided.
\end{abstract}

\section{Kata kunci}

Kerajaan, Khalifah, Islamisasi, Rusifikasi, Anaksasi

\section{A. Pendahuluan}

Persoalan dakwah Islam di Rusia merupakan topik yang menantang, bukan saja karena penelitian tentang Islam di wilayah ini masih sedikit, tetapi karena proses dakwah yang berlangsung di kawasan ini menunjukkan sebuah dakwah yang unik. Di Rusia, betapa pun kuatnya hegemoni negara dalam memaksakan kultur yang diinginkan bagi warganya, namun mendapatkan resistensi yang sangat kuat dari penduduk asli. Masyarakat muslim di wilayah ini merupakan 
kelompok minoritas, kenyataan ini tidak membuat mereka lemah terhadap desakan kuat pihak pemerintah kolonial, bahkan yang otoritarian sekalipun (Kettani, 1986: 55).

Gambaran keberadaan Islam di Rusia menciptakan potret bagaimana sebuah masyarakat yang telah belajar dari hegemoni budaya. Upaya intimidasi terhadap penyebaran dan penyerapan beberapa gagasan tidak akan berhasil, jika tidak mempertimbangkan upaya pengenalan yang lebih persuasif. Meskipun upaya ini bisa membawa akibat yang tidak disangka-sangka oleh penguasa, namun ketika perubahan yang secara gradual memunculkan kesadaran kritis masyarakat muslim tradisional saat itu, tentang perlunya pembaharuan pola pemikiran yang mereka anut selama ini, seperti yang terjadi dalam munculnya gerakan pembaharuan pemikiran Islam yang tertuang dalam beberapa tokoh penggeraknya.

Dalam pembahasan ini, kita akan memakai gagasan Antonio Gramsci yang menawarkan bagaimana hegemoni dijadikan konsep bahwa kelas penguasa tidak semata-mata memerintah dengan paksa, tetapi harus dilakukan melalui cara-cara persuasif. Dalam cara-cara persuasif inilah kelas yang tersubordinasi dipaksa untuk belajar dan melihat dirinya sendiri melalui kaca mata sang penguasa, yaitu dengan cara berterimakasih terhadap pendidikan yang diberikan dan dalam memandang kedudukan mereka dalam sistem (Burke: 1995: 85-86).

Signifikansi pendekatan ini untuk pengembangan ilmu dakwah dapat dilihat dalam fenomena dibalik upaya penciptaan hegemoni pemerintah kolonial Rusia yang ternyata menampilkan resistensi yang cukup kuat dari masyarakat muslim Tatar Volga. Pada akhirnya, proses ini justru memunculkan gagasan positif reformasi keagamaan yang secara sosial berguna bagi kemajuan masyarakat muslim Tatar Volga sendiri, khususnya dalam menyerap ide-ide baru yang tidak bertentangan dengan Islam, dan membuka mereka dengan dunia internasional.

Perlu diketahui bahwa masyarakat muslim di Rusia kebanyakan berdomisili di wilayah lembah sungai Volga, yaitu sungai utama di Rusia yang salah satu hulunya mengalir dari dataran tinggi dekat Kota Moskow menuju laut Kaspia. Komunitas muslim Rusia ini menamakan dirinya sebagai bangsa Volga Tatar, yaitu sebuah entitas pribumi yang 
merupakan gabungan antara ras pendatang Mongol, dan entitas asli suku-suku lokal di lembah Volga melalui perkawinan campur di antara mereka.

Generasi muslim di wilayah ini, memiliki sejarah gemilang dalam perkembangannya. Terdapat dinasti-dinasti Islam yang silih berganti menguasai peradaban, budaya, serta dominasi politik yang cukup disegani negara-negara sekitarnya. Bahkan generasi muslim ini, memiliki peran yang cukup penting dalam hubungan antar bangsa pada masanya, sebelum kemudian jatuh ke dalam aneksasi imperium Rusia pada 1552 (dalam Halperin, 1985; Frank, 1998; Pelenski, 1974; dan Rorlich, 1986).

Hal yang patut dicatat dalam perjuangan panjang keberadaan muslim di Rusia adalah kekuatan Islam sebagai agama yang mereka peluk selama berabad-abad merupakan faktor penentu keberhasilan mereka dalam memelihara identitas nasional, dan tradisi yang mereka anut, tetapi ini menandai gagalnya upaya asimilasi dengan etnis lain di Rusia, terutama pada masa pemerintah imperialis Rusia.

Seperti bangsa-bangsa Eropa yang lain, dalam menangani wilayah jajahannya, Rusia menganggap bahwa perluasan wilayah-seperti negeri-negeri di wilayah timur kekuasannya sampai ke Asia Tengahmerupakan bagian dari misi pemberdayaan sipil (civilizing mission). Secara khusus, upaya ini dikenal sebagai upaya rusifikasi yang memaksa untuk memakai bahasa dan kultur Rusia, serta perpindahan agama ke agama Kristen ortodoks. Dua faktor inilah yang menandai gagalnya upaya rusifikasi terhadap muslim Tatar Volga, karena kelompok masyarakat ini tidak mau kehilangan bahasa induk dan agama Islam yang mereka anut selama bearabad-abad.

\section{B. Asal Mula Bangsa Tatar Volga}

Menilik asal usulnya, suku bangsa Tatar Volga adalah suku Mongol Tatar yang mendiami wilayah paling Barat dari segenap pemegang identitas Turk, yaitu sebutan untuk ras suku-suku Asia yang mendiami wilayah bekas Uni Soviet. Ada dua kelompok besar dalam masyarakat Tatar Volga sekarang ini, yaitu suku bangsa Tatar Kazan dan suku Tatar Misyar. 
Penamaan nama etnik Tatar atau Tartar sendiri merujuk kepada identifikasi yang diberikan kepada kelompok suku bangsa Mongol pada abad ke-13. Di samping sebutan Tatar atau Tartar, beberapa nama etnik lokal yang kerap kali diberikan kepada mereka adalah Kazanis, Bulgar, dan Misyar yang menandai keragaman sub-etnik yang ada di dalamnya. Akan tetapi, secara umum mereka lebih menyukai penyebutannya dengan nama yang lebih menggambarkan kesatuan etnik bagi semua varian lokal yang menandai keanggotaan masyarakat suku ini.

Sejarah dakwah di masyarakat Tatar Volga dimulai sejak Islam memasuki wilayah Asia Tengah pada abad pertama hijrah (abad ke-7 M). Suku ini dapat dikatakan telah mengenal Islam sejak abad pertama agama Islam disebarkan. Dari Asia Tengah inilah, Islam kemudian berkembang luas memasuki wilayah lembah sungai Volga pada abad pertengahan. Dengan kedatangan Islam ke masyarakat lembah sungai Volga pada abad pertengahan, maka wilayah ini kemudian menjadi salah satu pusat peradaban Islam di dunia. Di wilayah ini, Islam dianut oleh penduduk yang berada dalam wilayah yang sangat luas, membentang dari laut Hitam di sebelah Barat sampai ke padang lumut Siberia di sebelah Timur.

Dakwah Islam sendiri telah mendapatkan simpati dan penganut dalam jumlah yang sangat besar. Utamanya diwakili suku-suku bangsa yang berbahasa Turki, yang disebut Bulghar atau Burdjan. Suku bangsa Bulghar ini sudah mendiami wilayah lembah sungai Volga sebelum invasi Mongol Tatar pada abad ke-13.

Suku ini berasal dari sebelah Selatan padang lumut Rusia, yang kemudian berpindah mendiami wilayah lembah Volga. Mereka mulai menghuni wilayah lembah Volga bersamaan dengan migrasi suku Hunnik. Mereka menggunakan huruf-huruf Cina dan aksara Manikean sebelum menggunakan tulisan Arab yang mulai diperkenalkan oleh para pendakwah Islam (Kettani, 1986: 57).

Perjalanan suku lembah Volga menunjukkan bukti akan ketinggian peradaban yang mereka capai, seperti ditunjukkan dalam periode keemasan yang dialami oleh tiga dinasti muslim yang menguasai wilayah itu, yaitu dinasti Kerajaan Bulghar, dinasti Golden Horde, dan empat pecahan kerajaan yang menjadi pewaris kerajaan Golden Horde, yaitu kesultanan (khanate) Kazan, Astrakhan, Siberia dan 
Krim. Periode pemerintahan independen ini berakhir ketika bangsa Rusia datang menganeksasi wilayah ini menjadi bagian dari wilayah jajahannya.

\section{Masa Kejayaan Kerajaan Islam}

Kerajaan Bulghar dibangun di jalur pertemuan antara sungai Volga dan sungai Kama, dengan ibukota pemerintahan di Kota Bilar. Bangunan utama kota ini dibangun dari pondasi batu kali, sementara dindingnya sudah memakai batu bata. Bangunan rumah orang Bulghar juga memiliki ruang bawah tanah (underground) yang dilengkapi dengan sistem pemanas langsung (central heating system). Bentuk bangunan menunjukkan pada kecanggihan arsitektur. Ini menandai ketinggian tingkat peradaban yang mereka miliki.

Sementara itu, produk utama pertanian mereka adalah gandum, di samping binatang ternak peliharaan. Export hasil panen produk pertanian kerajaan Bulghar dilaporkan telah menyelamatkan suku Suzdal dari paceklik pada 1024. Di samping sebagai negeri yang memiliki produksi pangan cukup melimpah untuk export, keuntungan lain yang mereka dapatkan melalui posisi strategis geopolitik kerajaan ini adalah ketika kerajaan Bulghar dikenal sebagai salah satu pusat perdagangan internasional.

Kota Bilar yang menjadi ibukota kerajaan ini berada di simpang jalan dan tempat pertemuan antara imperium Rusia di bagian Utara dan kerajaan Khazar di Iran di Selatan. Kota Bilar juga menjadi bagian dari rute perdagangan yang dilalui para pedagang muslim di Asia Tengah. Posisi strategis inilah yang membawa kerajaan Bulghar ke dalam hubungan diplomatik dan ekonomi yang erat dengan beberapa negara kuat pada waktu itu, termasuk kekhalifahan Abbasiah di Baghdad.

Kedekatan hubungan antara kerajaan Bulghar dan kekhalifahan Abbasiah, menurut M. Ali Kettani (1986: 57), terjadi dalam kaitan yang lebih mendalam ketika penguasa kerajaan Bulghar Yiltuwar Almush memeluk Islam di tangan seorang delegasi kekhalifahan Abbasiah yang dikirim Khalifah al-Muqtadir Billah yang bernama Ibn Fadlan. Berdasarkan aliansi politik antara kerajaan Bulghar dengan kekhalifahan Abbasiah inilah, julukan yang diberikan kepada Yiltuwar Almush diubah menjadi Amir Ja'far ibn Abd Allah. 
Dengan hubungan diplomatik yang bersahabat ini pulalah, Baghdad membangun sebuah kedutaan besarnya di Ibukota Bilar, yang sekaligus berfungsi sebagai penopang aktivitas dakwah Islam, termasuk di dalamnya kegiatan-kegiatan yang mengarah pada aktivitas pengenalan hukum Islam, pembangunan mesjid-mesjid, serta pendirian mimbar-mimbar untuk shalat Jumat.

Kedutaan besar ini juga memegang tanggung jawab penuh bagi terjalinnya proses islamisasi di seluruh negeri. Tugas-tugas ini sepertinya sejak awal sudah dapat dicapai oleh Ibn Fadlan, sebagaimana dilaporkan Istakhri, bahwa pada saat itu sudah ada sekitar 10.000 penduduk muslim di Kota Bilar dan kota lainnya di lembah Volga seperti Suwar (Hrbek, 1960: 1304b). Era kemakmuran kerajaan ini berakhir ketika tentara Tatar di bawah pimpinan Batu Khan menyerang dan merebut wilayah ini pada 1236.

Batu Khan menaklukkan Bulghar setelah mendapatkan perlawanan yang cukup sengit. Ia kemudian mendirikan kerajaan baru yang diberi nama Golden Horde dengan Ibukota Sarai. Ketinggian peradaban Islam yang terbentuk di sana, beberapa dekade kemudian diharuskan untuk menyerap unsur-unsur Mongol Tartar pada dasawarsa berikutnya. Akan tetapi, syiar agama Islam bersinar cerah kembali di lembah Volga ketika cucu Batu Khan yang bernama Uzbek memeluk Islam.

Dari sinilah, kaum Tatar sebenarnya kaum pendatang menjalani proses asimilasi bahasa dan kultural dengan bangsa Bulghar. Sebuah gambaran yang mewakili kondisi sosial dan politik pada era dinasti Golden Horde di lembah Volga digambarkan oleh Ibn Batutah dalam catatan perjalanannya mengunjungi wilayah-wilayah muslim yang sekarang dikenal sebagai wilayah bekas Uni Soviet. Ia mengatakan bahwa masyarakat muslim di wilayah itu berbicara dalam bahasa Turki dan mayoritas merupakan penganut mazhab Hanafi.

Kerajaan terbesar adalah kerajaan yang dipimpin oleh Sultan Uzbek, yang berada di Kota Al-Sara (atau Sarai) yang berada di tepi bantaran sungai Volga. Dibandingkan ketinggian peradaban yang dicapai oleh komunitas muslim di sana, Ibn Batutah menilai bahwa pada saat yang sama bangsa Rusia masih sangat lemah dan primitif. Ia menggambarkankannya orang-orang Rusia sebagai "penganut Kristen 
berambut pirang, bermata biru, berwajah jelek, dan berlaku sangat curang (Kettani, 1986: 59).

Pada akhir abad ke-14, upaya yang dilakukan oleh Sultan Toktamysh Khan, yang berasal dari the White Horde, guna menyatukan seluruh elemen Horde dalam kerajaan ditentang oleh Timur. Oleh karena itu, Golden Horde menderita serangan hebat yang dilakukan tentara Sultan Timur pada 1391. Kota Sarai dihancurkan sehingga Toktamysh harus melarikan diri keluar dari kota itu pada 1395. Akibat langsung dari kekalahan Golden Horde dari serangan tentara Sultan Timur ini adalah jumlah penduduk yang menyusut secara drastis akibat pembunuhan massal yang dilakukan tentara Sultan Timur. Sebagai tindak lanjut, setelah menyerang Holden Horde, pada musim gugur 1395, Sultan Timur memulai upaya barunya untuk meluaskan wilayah dengan maksud menyerang kerajaan Rusia yang berpusat di Moskow melalui penaklukan Riazan. Akan tetapi, upaya penyerangan terhenti sampai di situ, dan mereka urung menyerang Moskow. Akhirnya mereka memutuskan untuk kembali ke Asia Tengah.

Kekalahan Golden Horde oleh tentara Timur ini menjadikan Kerajaan Rusia di Moskow sebagai satu-satunya kekuatan militer besar yang paling siap melakukan ekspansi ke wilayah lembah sungai Volga yang nota bene baru saja mengalami kehancuran. Belakangan dilaporkan bahwa Jendral Edigu (Bahasa Rusia: Yedigey) muncul sebagai pewaris kekuasaan atas kerajaan Golden Horde, sebelum muncul disintegrasi yang pada gilirannya menciptakan pecahanpecahan kecil kesultanan (khanate) yang independen di Kazan, Astrakhan, Siberia dan Semenanjung Krimea (Kettani, 1986: 58).

Kesultanan Kazan muncul di pusat reruntuhan kerajaan Golden Horde, di lembah yang menandai pertemuan sungai Volga dan Kama. Dengan mengambil lokasi di bekas pusat kekuasaan Golden Horde, Kazan mewarisi letak strategis yang sejak dulu dimiliki, bahkan sejak masa kerajaan Bulghar. Kesultanan kecil ini mengalami kemajuan yang cukup pesat di tangan kekuasaan Ulu Muhammad, salah seorang putra Jalaluddin dan cucu Toktamysh. Ulu Muhammad memerintah Kazan antara tahun 1437 sampai 1445.

Kemajuan yang dicapai pada waktu itu diantaranya adalah kenyataan bahwa para perajian logam di Kazan merupakan orang-orang 
yang paling awal melakukan aktivitas peleburan besi. Ini sudah lama dilakukan oleh mereka sebelum aktivitas yang sama dilakukan oleh para perajin besi di Inggris. Kerajinan perhiasan, kulit dan keramik yang mereka hasilkan juga terkenal sampai keluar batas kerajaan. Para arsitek di Kazan juga telah berhasil membangun masjid dan istana yang besar dan megah. Bukti lain yang menandai pesatnya kemajuan yang dicapai kerajaan ini adalah bahwa setiap tahunnya terselenggara sebuah pameran dagang internasional yang menarik ribuan padagang asal Rusia dan negeri-negeri jauh di sebelah Timur. Akan tetapi, aneksasi kesultanan Kazan pada 1552 oleh tentara Tsar Ivan IV dengan julukan Ivan the Terrible, memutus kemakmuran ekonomi kesultanan ini.

Sejak saat itu, berakhirlah segala perlawanan terhadap kekaisaran Moskow, meskipun sebelumnya ada juga di antara para petinggi kerajaan yang memiliki hubungan dekat dengan Moskow dan terkadang menerima bantuan. Aneksasi Kazan juga membuat ketiga pecahan kerajaan Golden Horde lainnya menyerah. Astrakhan yang terletak sekitar 60 mil dari muara sungai Volga di Laut Kaspia menyerah pada 1556, sementara kesultanan Siberia ditaklukkan pada 1598 (Kettani, 1986: 58).

\section{Hegemoni dan Resistensi}

Ketika kesultanan Khazan jatuh ke tangan kekaisaran Moskow, upaya untuk menjadikan wilayah ini sebagai target kristenisasi, seperti lazim dilakukan oleh negeri-negeri Eropa terhadap wilayah koloni mereka jelas-jelas diungkapkan dalam pernyataan Tsar Ivan IV sendiri, "Biarkan kaum kafir menerima Tuhan yang sesungguhnya, menjadi bagian baru dari penduduk Rusia, dan ajak mereka untuk bersama-sama kita memuji the Holy Trinity dari abad ke abad" (Rorlich, 1986: 38).

Dari sinilah bermula proses yang dikenal dengan istilah rusifikasi, yaitu upaya untuk menggalakkan perpindahan agama ke Kristen Ortodoks sebagai langkah awal dalam mencapai asimilasi kultural dalam bidang-bidang lain, seperti hukum, pendidikan, dan kebijakan ekonomi.

Upaya ini mulanya bersifat lembut, tetapi tidak berhasil. Sebagai gantinya, dimulailah upaya pendekatan yang lebih menekan dalam bentuk pemaksaan untuk menganut Kristen. Kelompok masyarakat 
Tatar yang merasa tidak senang dengan pemaksaan untuk berpindah keyakinan ini, sama merasa tidak senangnya dengan banyaknya penduduk pendatang yang berkebangsaan Rusia.

Akibat ketidaksenangan ini, akhirnya mereka memberontak pada 1556. Tetapi pemberontakan ini dapat diredam, dan karena mereka menolak dikristenkan, mereka pun dilarang tinggal di Kota Kazan. Oleh karena itulah para pembangkang ini membentuk sebuah distrik baru yang dikenal dengan sebutan pemukiman Tatar Lama (Rorlich, 1986: 39).

Meskipun dipaksa, upaya kristenisasi ini tetap menemui kegagalan. Dalam sebuah surat yang dialamatkan kepada Tsar Fedor Ivanovich, walikota Hermogen mengeluhkan semakin banyaknya kaum Tatar yang telah mengalami pembaptisan, namun mereka segera kembali kepada agama Islam yang sebelumnya mereka anut.

Sementara yang lain tidak lebih dari sekedar pemeluk Kristen nominal semata. Tsar merespon keluhan ini dengan iming-iming properti bagi mereka yang bersedia memeluk Kristen, dengan hunian yang berdampingan dengan penduduk asal Rusia, serta sebidang tanah yang bisa saja berpindah kepemilikan.

Upaya ini pun tidak menemui hasil, justru sebaliknya, semakin keras perlakuan kaum imperial terhadap kaum muslim, hanya akan meningkatkan perasaan tidak puas suku Tatar terhadap pemerintah kolonial, yang membuat mereka semakin berani untuk mengadakan perlawanan secara terbuka, seperti yang terjadi pada 1669 dan 1670. Akibat lain dari kebijakan konversi paksa ini bermuara pada tingginya angka eksodus warga Tatar muslim ke wilayah Bukhara, dataran tinggi Kazakh, dan berbagai wilayah lain di Asia Tengah (Rorlich, 1986: 38).

Politik anti Islam yang diterapkan sejak awal aneksasi Rusia terhadap wilayah lembah sungai Volga, juga dilakukan penguasa selanjutnya, seperti Peter Agung, Ratu Anna Ivanova dan Elisabeth Petrovna (Rorlich, 1986: 38). Hanya saja, serangan secara fisik terhadap komunitas muslim baru dilakukan antara 1740-1743, di mana sebanyak 418 mesjid dihancurkan. Dan mesjid yang tersisa hanya 118 untuk seluruh wilayah lembah Volga. Upaya penghancuran berlanjut ketika pemerintah Moskow mendapatkan laporan bahwa 293 kaum animis dari suku Chuvash, lebih memilih menganut Islam daripada dipaksa 
memeluk Kristen. Akibatnya, beragam sanksi diberikan kepada kaum muslim Tatar yang telah menerima konversi suku Chuvash (Rorlich, 1986: 41).

Kebijakan yang memberatkan juga diterapkan dalam sistem fiskal, di mana kaum muslimin dan kaum pribumi non-muslim yang menolak masuk Kristen diharuskan untuk membayar pajak yang lebih tinggi, dan di bidang pendidikan (Rorlich, 1986: 41). Perubahan kebijakan yang lebih simpatik baru dijalankan ketika Caterine II memegang tampuk pemerintahan Rusia. Masa lalu kejayaan Tatar yang sangat bersinar menjadi pertimbangan Catherine II, ketika ia menyadari bahwa misi ekspansi Moskow ke arah timur, baru bisa mencapai sukses jika penindasan terhadap kaum muslim dihentikan (Rorlich, 1986: 42).

Dari sini, secara politik agama Islam tidak lagi dijadikan musuh, tetapi lebih dijadikan sebagai alat politik, ketika dengan Islam dan perantaraan para pedagang Tatar inilah, maka kontak perdagangan antara Rusia dengan negeri-negeri dan kesultanan muslim di Asia Tengah dan dataran tinggi Kazakh dapat terjalin.

Peraturan yang dibuat antara 1763 sampai 1776, merefleksikan pemahaman Catherine II terhadap kenyataan ini. Bahwa kaum Tatar diperbolehkan untuk melakukan transaksi dagang, dan mengelola perusahaan-perusahan komersial menyebabkan banyak kaum Tatar yang berpindah ke dataran tinggi Kazakh.

Perpindahan ini mendatangkan keuntungan, ketika para imigran mendirikan kantong-kantong komersial yang sangat berguna dalam menjalin transaksi dagang dengan Asia Tengah, di samping juga menciptakan hunian baru bagi kaum muslim. Mereka juga banyak mengirimkan anak-anak mereka, ke madrasah-madrasah terkenal di Bukhara untuk mendapatkan pendidikan lanjutan.

Sementara itu, kaum Tatar yang tetap tinggal di Kota Kazan dapat mengumpulkan kekayaan, yang kemudian membentuk kelompokkelompok pedagang kelas menengah yang kaya pada abad ke-19 (Rorlich, 1986: 43). Catherine II juga menetapkan peraturan tentang jaminan akan kebebasan beragama dan menjalankan ibadah, meskipun hal ini bukan sama sekali mencerminkan simpatinya kepada Islam. Lantaran hal itu lebih sebagai sikap ketakutannya terhadap revolusi 
Purgachev, di mana mayoritas penduduk pribumi, termasuk kaum Tatar, terlibat di dalamnya secara aktif.

Selain mengkampanyekan kebebasan beragama, Catherine II juga mendukung pendirian Dewan Spiritual Muslim (Spiritual Muslim Assembly), menggaji beberapa mullah yang loyal kepada pemerintah, dan memberikan dana bagi pembangunan kembali mesjid dan sekolahsekolah Islam.

Politik imperial yang semula anti-Islam, kini mulai tampak menonjolkan image kedekatan dengan Islam. Di satu sisi, sikap ini menguntungkan kaum muslim, tetapi di sisi lain hal itu menjadi alat efektif upaya pemerintah imperial, dalam mengontrol aktivitas para tokoh agama dalam komunitas muslim Tatar.

Dengan terciptanya komunitas muslim yang terpuaskan dan antusias di Rusia, Catherine II percaya jika hal tersebut pada saatnya berguna bagi tercapainya target anaksasi imperial yang lebih luas ke Asia Tengah (Fisher, 1968: 548). Kesan yang tampak dari kebijakan politik yang dilakukan Catherine II terhadap Islam, bukanlah bentuk upaya rusifikasi terhadap kaum muslim secara langsung, tetapi hanya bermaksud menggiring mereka agar sepenuhnya berada di bawah kendali administrasi Rusia.

Dengan sendirinya, pemerintah imperial Moskow dapat secara lebih leluasa mengontrol kegiatan yang dilakukan oleh tokoh-tokoh Islam, yang pada akhirnya mau tidak mau terpaksa bersentuhan dengan penggunaan bahasa Rusia sebagai bahasa resmi dalam urusan administrasi pemerintah, dan penggunaannya lebih jauh lagi di dalam isntitusi pendidikan. Pengenalan bahasa Rusia bagi kalangan musim Tatar, paling tidak bisa ditafsirkan sebagai tanda akan tercapainya salah satu target rusifikasi, di luar upaya kristenisasi yang gagal total.

Belum tercapainya target kristenisasi terhadap kalangan muslim Tatar, agaknya menjadi penyebab bagi terulangnya kebijakan yang menekan terhadap kelompok minoritas muslim Tatar ini, oleh para penguasa Moskow sepeninggal Catherine II, seperti yang dilakukan Tsar Nicholas I (1825-1855) yang kembali mengaktifkan program missionaris Kristen terhadap kalangan muslim Tatar (Rorlich, 1986: 44). 
Ini bisa dimengerti, mengingat faktor kegagalan upaya mengkristenkan kaum muslim Tatar ini, termasuk kegagalan menarik kaum animis ke dalam agama Kristen, karena ternyata mereka bahkan tertarik untuk memeluk Islam. Ini merupakan salah satu elemen pokok upaya rusifikasi yang belum mendapatkan hasil yang memuaskan.

\section{E. Munculnya Gagasan Reformasi}

Entah disadari atau tidak, masuknya bahasa Rusia dalam kurikulum pendidikan Islam di Kazan, telah menyadarkan kalangan muslim pembaharu akan arti penting ilmu pengetahuan di luar pengetahuan agama. Dan pada akhirnya menciptakan iklim kondusif terciptanya reformasi pemikiran agama. Terciptalah elemen-elemen perubahan dalam kultur keagamaan masyarakat muslim Tatar abad ke19, yaitu sebagai minoritas yang mampu mempertahankan identitasnya selama hidup bersama di dalam kekaisaran Kristen yang kuat.

Komunitas muslim Tatar pada kenyataannya tidak sepenuhnya menolak asimilasi, kecuali ketika mereka diminta untuk berpindah menjadi penganut Kristen. Konsekuensi yang bisa dilihat akibat penerimaan rusifikasi secara selektif ini, mereka melakukan penelaahan kritis secara berkelanjutan terhadap nilai-nilai tradisional dalam agama, sebagaimana mereka juga mulai mempertimbangkan tempat mereka di dalam komunitas Rusia. Dalam proses itu, menurut Azade-Ayse Rorlich, kesadaran ini berkembang menjadi sebuah makna komunitas baru, dan masyarakat Tatar mulai membentuk karakter sekulernya sendiri (Rorlich, 1986: 48).

Oleh karena itu, ada beberapa bentuk upaya reformasi yang dilakukan kelompok minoritas muslim ini. Berawal dari upaya penelaahan ulang terhadap pemikiran keagamaan pada akhir abad ke18 sampai awal abad ke-19. Proses reformasi mengarah kepada terciptanya reformasi kultural dan pendidikan, serta reformasi dimensi politik pada awal abad ke-20.

Beberapa eksponen pembaharu yang bisa disebut mewakili gerakan reformasi pada tingkat pemikiran keagamaan sampai kultural dan pendidikan dari generasi ke generasi, di antaranya Abu Nasr alKursavi (1726-1813), Syihabeddin Merjani (1818-1889), dan Rizaeddin Fahreddin (1858-1936) (Rorlich, 1986: 49-59). Selain itu ada juga tokoh 
yang bernama Musa Jarullah Bigi (1870-1949), dan Ismail Bek Gaprisnki (1851-1914) yang dikenal Ismail Gaspirali yang sangat berjasa dalam melanjutkan gagasan ini kepada generasi selanjutnya.

\section{Abu Nasr al-Kursavi (1726-1813)}

Kursavi adalah seorang mufassir Al-Quran yang cukup serius. Gagasannya menekankan pada pentingnya pengungkapakan ijtihad bagi setiap kaum muslim, sehingga praktek ijtihad ini bukan saja diperuntukkan bagi mereka yang memiliki keahlian di bidang agama.

Pesan Kursavi pada intinya adalah memperkuat makna Islam sebagai agama sekaligus menjadi way of life. Gagasan pembaharuan kedua yang dilontarkan Kursavi adalah setiap sarjana Islam harus memiliki hak untuk menghadirkan penafsirannya sendiri terhadap AlQuran dan Hadis, dalam upaya menemukan jawaban yang benar menyangkut pertanyaan-pertanyaan tertentu. Atas dasar ini, ia menolak sikap taqlid dan menjadikan tafsir sebagai kriteria penting bagi vitalitas dogma Islam.

Gagasan ini memicu reaksi keras Emir Haidar dari Bukhara, sehingga Kursavi harus meninggalkan kota (Rorlich, 1986: 49-50). Pengungkapan ide pembaharuan yang terlalu awal pada masanya, di samping faktor lain tidak mendukung ketika suara pembaharuan ini membuat ide ini hanya dianggap sebagai suara tunggal yang tidak mendapat sambutan dalam basis sosial yang lebih luas. Akan tetapi, tidak dapat dipungkiri bahwa suara inilah yang memicu tumbuhnya gagasan-gagasan pembaharuan yang menandai reformasi masa-masa selanjutnya.

\section{Syihabeddin Merjani (1818-1889)}

Shihabeddin Merjani merupakan penerus gagasan Kursavi. Selama menuntut ilmu di Bukhara, ia meneliti ide-ide Kursavi dan menuliskannya dalam Tanbihi Abna' al-Asr bi tanzih Anba'i Abu Nasr. Gagasan pembaharuan dalam bidang pendidikan, dituangkannya ketika kembali ke Kazan pada 1849 dengan menyerukan agar madrasah membersihkan diri dari karya-karya filsafat skolastik yang konservatif. Ia juga mengusulkan selain Al-Quran dan Hadis, sejarah Islam juga 
diajarkan di semua madrasah. Pekerjaannya di Universitas Kazan banyak berhubungan dengan professor-professor berkebangsan Rusia dan Jerman, yang meneguhkan keyakinannya akan pentingnya ilmu pengetahuan dan bahasa Rusia.

Menurut Merjani, pentingnya sains menemukan jalan pintasnya dengan belajar sains Rusia. Hal mana terbuka bagi setiap muslim asalkan ia mengerti bahasa Rusia dengan baik. Agar tidak menimbulkan kecurigaan akan idenya dengan upaya rusifikasi, Merjani berpesan khusus, ia tidak pernah memakai idiom dalam bahasa Rusia di dalam masyarakat Tatar, ataupun memakai kata akhir Rusia bagi nama keluarga Tatar, dan tidak juga memakai penanggalan Masehi. Ketiga contoh ini mencerminkan pesan tersembunyi kepada kaum Tatar bahwa memiliki pengetahuan tentang sains dan bahasa Rusia, tidak serta merta berarti harus kehilangan identitas keislaman (rorlich, 1986: 52).

\section{Rizaeddin Fahreddin (1858-1936)}

Rizaeddin Fahreddin merupakan murid Merjani yang paling dikenal. Ia berkenalan dengan gagasan-gagasan Merjani ketika bersekolah di madrasah. Gagasan-gagasan yang ia cermati dengan mendalam sebelum ia memformulasikan pandangan dirinya tentang agama dan masa depan muslim Rusia.

Selain Merjani, elemen lain yang mempengaruhi pola pemikiran Fahreddin adalah koran Terjuman yang diterbitkan intelektual PanTurkis di Semenanjung Krimea, yaitu Ismail Gasprali; dan pengaruh pemikiran Jamaluddin Al-Afghani yang bertemu Fahreddin di St. Petersburg. Pengaruh lain juga berasal dari gagasan-gagasan Muhammad Abduh. Fahreddin menulis banyak karya, terutama tentang teologi Islam. Di samping itu, ia juga mengabdikan dirinya untuk menjawab isu-isu sosial seperti pendidikan bagi wanita dan peran keluarga di dalam Islam.

Seperti Merjani, Fahreddin menilai pentingnya sains, bahasa Rusia dan sekolah. Lebih jauh ia juga menegaskan pandangannya tentang keserasian antara agama dan sains. Hal ini memberi dampak pada pola pikirnya yang sangat rasional, sehingga apa yang dianggapnya bisa diterima hanyalah hal-hal yang secara saintifik baik dan etis secara 
moral. Meskipun begitu ia tetap mengedepankan sikap toleran terhadap perbedaan pendapat.

\section{Musa Jarullah Bigi (1870-1949)}

Sebagai murid Merjani, Fahreddin tidaklah sendiri, karena teman seperguruan terbaiknya Musa Jarullah Bigi (1870-1949) juga membawa nuansa baru dalam perkembangan pemikiran keagamaan di komunitas Volga Tatar. Berkat peran para pemikir pembaharu inilah, muslim Rusia melahirkan gerakan Jadidism yang secara aktif berperan dalam politik (Rorlich, 1986: 59-64).

\section{Ismail Bek Gaprisnki (1851-1914)}

Atas dasar penelaahan pemikiran agama, dan melalui prakarsa reformasi dalam dunia pendidikan, gagasan reformasi bergulir menjadi sebuah gerakan politik dengan nama Jadidisme. Pemrakarsa gerakan ini adalah Ismail Bek Gaprisnki (1851-1914), editor koran Terjuman yang terbit di semenanjung Krimea. Gaprinski tidak saja mendapatkan pengaruh besar di Rusia, seperti ditunjukkan terhadap pola pemikiran Rizaeddin Fahreddin, tetapi juga bagi muslim di Asia Tengah.

Dalam tulisannya yang berjudul The Moslem of Russia, ia menuliskan pandangannya sebagai tokoh yang memberikan pencerahan. Ia meneguhkan bahwa tergabungnya teritori penduduk muslim yang luas ke dalam Rusia merupakan sebuah kebaikan bagi Islam itu sendiri. Ia menolak pandangan ulama konservatif Rusia yang memandang Rusia sebagai darul harb bagi kalangan muslim. Ia menuliskan juga bahwa kesultanan-kesultanan Ryazan, Kazan, Astrakhan, Siberia dan Krimea, Transkaukasia, dan Asia Tengah telah bergabung, dan peralihan penduduk muslim dengan wilayahnya yang sangat kaya ke dalam naungan Rusia, membuat Rusia menjadi perantara alami antara Eropa dan Asia, antara ilmu pengetahuan dan kebodohan, serta antara kemajuan dan kemandegan (Gaprinski dalam Polonskaya dan Malashenko, 1994: 59-60).

Kontribusi utama gerakan Jadidisme ini adalah penyususan metode baru pengajaran (usuli jadid). Pada 1884, Gaprinski mendirikan maktab pertama yang menerapkan metode baru pengajaran. Pada saat 
yang sama, ia juga mengusulkan reformasi pendidikan madrasah, termasuk meminta para ahli Rusia untuk membantu kaum muslimin dalam menjalankan program pembaruan itu.

Pemikiran pembaruan Gaprinski ini ditentang baik oleh kelompok muslim konservatif yang dikenal dengan julukan qadimi, maupun juga dari kalangan missionaris yang menginginkan kaum muslimin ini menjadi orang Rusia, rusifikasi, atau rusianisasi yang selain berbahasa Rusia juga menganut Kristen Ortodoks.

Gagasan pembaruan yang didengungkan kelompok Jadidis ini, selain mendorong kaum muslim untuk menguasai bahasa Rusia, juga mendorong penguasaan kaum muslim terhadap bahasa-bahasa lain. Seorang anak, menurutnya, harus mengerti bahasa Turki agar bisa berbicara dengan keluarganya. Begitu juga pengetahuan tentang bahasa Persia untuk memahami syair-syair dan budaya. Selain itu, juga mesti mengenal bahasa Arab sebagai bahasa agama. Sementara itu, bahasa Rusia juga diperlukan untuk mempromosikan perkembangan ekonomi dan industri. Dan terakhir perlunya penguasaan terhadap salah satu bahasa Eropa-bahasa Inggris, Perancis, atau Jerman-agar bisa berkomunikasi dengan negara lain.

Gerakan Jadidisme yang dipelopori Ismail Gaprinski ini, menandai kelanjutan gerakan pembaruan yang berpartispasi politik kaum muslim Rusia di masa-masa selanjutnya, ketika Tsar Nicholas II mengumumkan Manifesto Politik pada 17 Oktober 1905, yang menyuarakan kebebasan hak dan kebebasan setiap warga Rusia menyangkut kebebasan mengemukakan pendapat, kebebasan pers, berkumpul dan berorganisasi (Rorlich, 1986: 105). Kaum muslim Tatar Volga menyambut revolusi 1905 ini, dengan harapan akan terakomodasinya partisipasi politik yang lebih baik berkat kematangan yang ditunjukkan oleh gerakan Jadidisme.

Di sini, partisipasi politik kaum muslim terjadi dalam pola hubungan yang lebih setara dalam aktivitas parlemen Rusia Duma, antara 1906-1917, bahkan ketika kelompok Bolshevik memenangkan revolusi pada Februari 1917. Revolusi yang terakhir ini, mengubah Rusia menjadi sebuah Uni, negara yang terdiri dari persatuan badanbadan legislatif (soviet) dengan wilayah yang lebih luas, daripada wilayah Rusia yang pada awalnya beberapa wilayah muslim di Asia 
Tengah, seperti Azerbaijan, Turkmenistan, Uzbekistan, Kyrgiztan, dan Tajikistan.

Dalam sejarah perkembangan Rusia modern, kesediaan komunitas muslim Tatar Volga dalam mengadaptasi sebagian programprogram rusifikasi, terutama yang terkait aspek budaya, di luar resistensi mereka terhadap kebijakan konversi paksa Kristen Ortodox, memberikan kondisi kehidupan sosial politik yang lebih baik. Ini dapat dilihat dari pemberian otonomi khusus yang berujung pada terbentuknya Republik Otonom Soviet Sosialis Tatar (TASSR) pada 1920.

Terbentuknya TASSR dapat pula dikatakan sebagai kemenangan kelompok muslim nasionalis komunis, terhadap kampanye Gerakan Pan-Turki. Ini juga menjadi keberhasilan reformasi yang diserukan Ismail Gaprinski, tentang perlunya kaum muslimin bergabung secara politik dengan Rusia.

Di sisi lain, tergabungnya kekuatan Islam di soviet-soviet Asia Tengah, bersama minoritas muslim Rusia dalam bendera Uni Soviet, kerap melahirkan praktek politisasi Islam. Pada satu sisi, kondisi ini menguntungkan mereka ketika negara-negara Arab dan dunia Islam umumnya bersimpati.

Upaya ini penting dalam kehidupan sosial dan politik muslim Tatar Volga, dalam kerangka kompetisi menghadapi kekuatan Barat. Meskipun bagi Uni Soviet sendiri, tujuan politisasi Islam ini tidak lain dimaksudkan mencegah Islam untuk menjadi kekuatan sosial dan politik yang independen. Namun dengan pendekatan ini, telah menampilkan kesan bahwa pemerintahan Uni Soviet memberikan kesempatan bagi Islam untuk bebas berkembang (Hunter, 1996: 292).

Memang pada prakteknya, kesempatan bagi Islam untuk berkembang selama masa pemerintahan Uni Soviet, tidaklah sebagus yang dikesankan. Akan tetapi, melihat perkembangan Islam dewasa ini, dakwah Islam semakin menemukan titik terang perkembangannya yang sangat mengesankan, mengingat semakin menurunnya populasi penduduk Rusia dari tahun ke tahun. ${ }^{1}$ Dari 144 juta penduduk negara

1 Lihat analysis Daniel Pipes dalam blognya tentang prediksi muslim menjadi mayoritas di Rusia dekade 2050 nanti, http://www.danielpipes.org/blog/2005/08/ predicting-a-majority-muslim-russia. 
Federasi Rusia dewasa ini, 23 juta di antaranya atau $16 \%$ adalah muslim. Jumlah ini akan semakin meningkat dengan semakin banyaknya konversi dari Kristen ortodoks ke dalam agama Islam, dari penduduk Rusia sendiri. ${ }^{2}$

\section{F. Penutup}

Keberadaan Islam dan komunitas muslim di Rusia pada hakikatnya merupakan entitas asal, baik secara kultural maupun politik. Hanya saja, mereka mulai menjadi seperti orang asing di rumahnya sendiri saat imperium Moskow menaklukkan lembah Volga. Hegemoni budaya melalui program rusifikasi yang dilakukan oleh penguasa imperial Rusia pasca anekasi Kazan pada 1552, menjadikan Islam sebagai target utama yang harus dihapuskan melalui gencarnya misi kristenisasi. Untung saja, keteguhan bangsa Volga Tatar dalam memeluk Islam dan melestarikan identitas nasionalnya, menandai keberhasilan sikap mempertahankan Islam sebagai agama mereka.

Resistensi ini menjadi buah keberhasilan dakwah yang mungkin manfaatnya hanya bisa dilihat dewasa ini, ketika hak kebebasan beragama benar-benar dipraktekkan. Namun, resistensi saja tidak cukup ketika gempuran hegemoni yang secara persuasif mendekatkan komunitas muslim dengan keinginan negara melalui pemakaian bahasa Rusia.

Pemakaian bahasa Rusia yang ditambah dengan pergaulan global, memberi penyadaran akan perlunya gagasan reformasi pemikiran Islam. Dari sini, aktivitas dakwah tidak saja dilakukan secara pasif dengan mempertahankan keyakinan Islam dari gempuran hegemoni dan tekanan kristenisasi, tetapi menjadi berbuah manis pada penerimaan terhadap keberadaan masyarakat muslim Tatar Rusia di mata dunia secara umum, dan Islam khususnya. Dan pada titik yang lebih aktif, mampu memancarkan cahaya kebenaran Islam bagi komunitas agama lain di Rusia.[]

2 Salah satunya adalah kasus pendeta ortodoks, Viacheslav Polosin, yang masuk Islam pada 1999. Lihat http://www.themodernreligion.com/convert/convert polosin. htm. 


\section{DAFTAR PUSTAKA}

Abudi, M. Nasir. 1999. Biladu Tatar wa Bulghar. Makkah: Rabitah Alam Islami.

Burke, P. 1995. History and Social Theory. Cambridge: Polity Press.

Fisher, Alan W. 1968. "Enlightened Despotism and Islam under Catherine II" dalam Slavic Review, vol. xxvii.

Frank, Allen J. 1998. Islamic Historiography and Bulghar Identity among the Tatars and Bashkir of Russia. Leiden: Brill.

Golden, P.B. 2000. "Tatar" dalam The Encyclopaedia of Islam (EI $\left.{ }^{2}\right), \mathrm{X}$, 370a.

Halperin, Charles. D. 1985. Russia and the Golden Horde. Bloomington: Indiana University Press.

Hrbek, I. 1960. "Bulghar” dalam EI², vol. I, 1304b.

Hunter, Shireen. 1996. "Islam in Post Independence Central Asia: Internal and External Dimensions" dalam Journal of Islamic Studies, vol. VII, no. 2, 1996.

Kettani, M. Ali. 1986. Muslim Minorities in the World Today. London: Mansell.

Kirimli, Hakan. 1996. National Movements and national Identity among the Crimean Tatars (1905-1916), Leiden: Brill.

Pelenski, J. 1974. Russia and Kazan, Conquest and Imperial Ideology (1438-1560s). Den Haag: Mouton.

Polonskaya, L. and Malashenko, A. 1994. Islam in Central Asia, Reading: Ithaca.

Rieber, A.J. 1982. Merchants and Intrepeneurs in Imperial Russia. Chapel Hill.

Rorlich, Azade-Ayse. 1986. The Volga Tatars, A Profile in National Resilience. Stanford, California: Hoover Institution Press

http://www.danielpipes.org/blog/2005/08/predicting-a-majoritymuslim-russia, diakses 13-08-2010.

http://www.themodernreligion.com/convert/convert_polosin.htm diakses 13-08-2010. 